\title{
International Public Sector Accounting Standard (IPSAS) 12-Inventories: Determining exemplary requirements for military logistics systems
}

\author{
Holger SCHEPPELMANN ${ }^{1}$
}

\begin{abstract}
In this paper the author shows that it is conceptually possible to derive from International Public Sector Accounting Standard (IPSAS) 12-Inventories exemplary requirements that can be used as a basis to assess in principle the compliance of military logistics systems with IPSAS 12. However, the utility of isolated requirements for compliance with IPSAS 12 is limited, since these requirements certainly need to be integrated with requirements derived from other IPSASs and with requirements related to the accounting system used to prepare IPSAS annual financial statements. As a result of such a requirement's integration process it is very likely that noticeable changes and/or augmentations of the proposed exemplary requirements for compliance with IPSAS 12 will turn out to be necessary.
\end{abstract}

\section{Introduction}

The intention of this paper is to contribute to closing the existing gap in the current literature with regard to practical issues typically encountered in real world implementations of International Public Sector Accounting Standards (IPSAS). While in an earlier paper [1] the question how and to what extent existing military logistics data can be reused for IPSAS financial reporting has been discussed, this paper intends to focus on the necessary capabilities military logistics system need to have in order to store and process financial data, which meet the requirements of IPSAS 12-Inventories.

Chan [2] pointed out in his analysis of the institutional and conceptual issues related to IPSAS that IPSAS neglect the system capability, i.e. the "infrastructure for collecting, recording, and summarizing financial data”, which implies, in his view, the necessity of using (for IPSAS compliant annual financial statements) an accounting (information) system that has as necessary capabilities:

“(1) the accounting equation, assets = liabilities + net assets, as its conceptual foundation;

(2) a detailed chart of accounts for the elements of the accounting equation, as well as revenues and expenses as changes in net assets;

(3) a double-entry recording system; and

(4) the ability to translate standards (such as IPSAS) into specific policies and procedures applicable to the organization concerned" [2],

which "have to be incorporated in the hardware and software of the accounting system, $(\ldots)$..[2]

1 Holger.Scheppelmann@gmx.net 
The intention of this paper is therefore to determine the requirements for military logistics systems that need to comply with IPSAS in order to support the preparation of IPSAS financial statements of a NATO-led or UN-led International Military Headquarters. For current and future International Military Headquarters (HQs) the compliance of their military logistics systems with IPSAS has become relevant, since both organizations decided in 2002 and 2006, respectively, to use IPSAS as the standards for the preparation of their annual financial statements.

Determining a set of exemplary IPSAS 12 requirements allows HQs to assess the degree to which their currently operated military logistics systems comply with IPSAS 12 and can also provide a basis for determining the requirements of planned future military logistics systems. The discussion in this paper is therefore applicable to a broad range of logistics systems from manual paper-based logistics systems to fully automated logistics systems that may be part of an Enterprise Resource Planning (ERP) system.

\section{Scope of requirements}

IPSAS requirements can be grouped in two major categories: requirements for IPSAS financial statements as a whole, such as qualitative characteristics like relevance, faithful representation, understandability, timeliness, comparability, verifiability, materiality, cost-benefit, the fundamental principles of completeness [3], and requirements mandated by a specific IPSAS standard, such as e.g. IPSAS 12-Inventories or IPSAS 17-Property, Plant and Equipment. From an IPSAS point of view the scope of this paper is therefore limited to those requirements that can be directly derived from IPSAS 12. [4]

Likewise, a discussion of the more generic requirements for software applications used to process information to be used in the preparation of IPSAS financial statements will be considered to be outside of the scope of this paper. Examples for such generic requirements include e.g. controls to ensure the completeness of processed data or the realisation of segregation of incompatible duties through roles-and-responsibility concepts as can be seen from the ISACA IT Auditing Guideline G21 Enterprise Resource Planning (ERP) Systems Review [5] or from the ISACA Switzerland Chapter's Guide to Auditing IT Applications [6]. The United States Government Accounting Office's Inventory Systems Checklist provides guidance for assessing the inventory management capabilities of an inventory system and its compliance with the applicable United States statutory requirements. [7]

\section{Possible bases for IPSAS requirements analysis}

International Public Sector Accounting Standards (IPSAS) are conceptually derived from International Financial Reporting Standards (IFRS) or the earlier International Accounting Standards (IAS), respectively. A future goal of the International Public Sector Accounting Standards Board (IPSASB) is the convergence of IAS/IFRS and IPSAS. [8] [9] Guidance on the IFRS requirements for private sector inventory systems could therefore in principle form mutatis mutandis the basis for IPSAS requirements of public sector (including military) logistics systems.

While an Exposure Draft is foreseen for September 2013 [10], to date there is no IPSAS on the first-time adoption of IPSAS. In addition IFRS 1 First-Time Adoption of IFRS [11] 
does not discuss any practical implementation issues related to the first-time adoption of IFRS or, by extension, IPSAS. Likewise, the IPSASB Recommended Practice Guidelines [12] [13], and the official SIC-Interpretations (for IAS) [14], and IFRIC-Interpretations (for IFRS) [15] all focus exclusively on accounting issues in the narrower sense.

While noticeably more practically oriented than the above authoritative guidance, the IPSASB Study 14 Transition to the Accrual Basis of Accounting: Guidance for Governments and Government Entities [16] includes nonetheless only a rather limited discussion of the role logistics systems play in the implementation of IPSAS, despite the fact that traditional governmental accounting standards, such as cash-based accounting usually do not mandate that all assets - including in particular items of inventory and items of property, plant and equipment have to be reported in the annual financial statements, as Bergmann emphasizes in his criticism of cash-based accounting. [17]

Although there is already substantial literature on the major issues typically encountered in IAS/IFRS implementations, only very few authors, such as e.g. Bastos [18], or Brown [19] give at least some high-level indications of the areas, where financial information systems have to be reviewed in concreto in order to ascertain that they are capable of providing the financial information necessary for the preparation of IAS/IFRS compliant financial statements.

The comparative study of Christiaens and Reyniers [20] on the impact of IPSAS on reforming governmental financial information systems concentrates on conceptual issues at the central government or local government level rather than on requirements for systems to be used in real-world implementations of IPSAS.

The compliance of information systems with laws, rules, regulations or standards is only implicitly discussed in the existing literature. One possible explanation could be that compliance of information systems are seen largely as one of many requirements an existing or planned system has to fulfill. Additionally, for most systems the documentation made available by the software vendors will be limited to user documentation and to a certain extent of technical documentation, leaving systems essentially as black boxes with limited possibilities to actually test them for compliance. This is particularly problematic with regard to most ERP systems, where as a consequence of the numerous configuration possibilities through parametrisations two real-world ERP implementations can almost never be considered identical. The example of the compliance certification of the Oracle 12 E-Business Suite for compliance, German Generally Accepted Accounting Principles (Grundsätze ordnungsmässiger Buchführung), shows that a statement of compliance is directly linked to a certain, well defined set of parameters used for the configuration of the ERP-System. [21]

From the above overview of the existing literature it can therefore be seen that there is indeed a need to determine the requirements for both existing and planned military logistics systems that need to comply with IPSAS 12 Inventories.

\section{The concept of systems requirements analysis}

Grady defines a requirement as "an essential attribute or characteristic for a system or an element of a system” [22] and the analysis of system requirements is, as Boehm notes in his discussion of the historical development of software engineering in the 20th and $21^{\text {st }}$ century, always an early, if not the first, activity in the various software development life cycle models that emerged in the recent decades. [23] 
The challenge in requirements analysis is to determine and document the system requirements in such a way that they are unambiguous and can be objectively validated and verified $(\mathrm{V} \& \mathrm{~V})$ or - in short - that they are testable. [24]

For developing requirement documents for large-scale systems Grady [22] recommends following the guidance from United States Military Standards (MIL-STD) 961D/E [25] and the successor standards of MIL-STD-490A, which define inter alia the structure, language style, and format of such requirements documents. MIL-STD-961E specifies that "(...) 'shall' (...) shall be used (...) whenever a requirement is intended to express a provision that is binding.", which - together with the expression "in accordance with" for citing references is considered to be a straightforward approach for documenting IPSAS requirements. [25]

\section{Exemplary IPSAS 12 requirements for military logistics systems}

While all items typically managed with a military logistics systems can be classified through a NATO Supply Classification Code, not all items will necessarily be items of inventories in accordance with IPSAS 12 Inventories, since some items may require reporting according to IPSAS 17 Property, Plant and Equipment or — in the case of Group 87 Agricultural Supplies and Group 88 Live Animals - in accordance with IPSAS 27. Agriculture is outside the scope of this paper, since it should be reported in accordance with IPSAS 27 Agriculture. [1]

Recapitulating that IPSAS does not consider system capabilities — as pointed out by Chan [2] - a real-world implementation of IPSAS inevitably encounters the question, which actual capabilities of a system used - alone, or together with other systems - are needed in order to support the preparation of IPSAS compliant financial statements. Depending on the nature of the entity, the system concerned will need to comply with a larger or smaller number of other IPSAS standards in addition to IPSAS 12.

For deriving the requirements from the IPSAS 12 standard the following approach has been used: The text of the standard has been analysed and the intended result of an individual provision of the standard has to be worded in such a way that the result is a requirements statement that is unambiguous and can be verified and validated, but is at the same time neutrally worded, so that the requirements can be used to both analyse a broad range of comparable systems, such as e.g. paper-based logistics systems, Government-Off-The-Shelf (GOTS) logistics systems as well as Commercial-Off-The-Shelf (COTS) logistics systems and to provide, at the same time, requirements for the development and implementation of new systems.

Based on the above discussion the following exemplary requirements are proposed as basic requirements for compliance of a military inventory logistics system with IPSAS 12:

\section{Minimum item properties in accordance with IPSAS 12}

a. The system shall for each item that meets the definition of IPSAS 12 and can be classified with a NATO Supply Classification Code (except Groups 87 and 88) provide at least the following item properties (different methods for realisation of the requirement are possible, the property names and property values are provided below for illustration of the concepts only) [26]: 


\section{Property Name}

ItemType

ItemTransactionType

ItemInterchangeable

ItemCost

ItemFairValue

ItemCarryingAmount

ItemDeferredSettlement

ItemFinancingElement

ItemFinancingElementApportioning

ItemDistribution

ItemCurrentReplacementCost

ItemCostFormula

ItemWeightedAverageCost

ItemWritedownAmount

ItemReversedWritedownAmount

ItemExpense

ItemQuantity

ItemDescription

ItemFairValueLessCostsToSell

ItemTransactionHistory

ItemNATOStocknumber

ItemBudgetAccount

ItemAssetAccount

ItemExpenseAccount

\section{Proposed Property Values}

\author{
Inventory, PPE \\ ExchangeTransaction, NonExchangeTransaction \\ OrdinarilyInterchangeable, \\ NotOrdinarilyInterchangeable \\ Monetary amount \\ Monetary amount \\ ItemCost, ItemFairValue \\ Yes, No \\ Monetary amount \\ List of monetary amounts \\ Yes, No \\ Monetary amount \\ FirstInFirstOut, WeightedAverageCost \\ Monetary amount \\ Monetary amount \\ Monetary amount \\ Monetary amount \\ nteger number $(0,1, \ldots \mathrm{N})$ \\ Text in accordance with nomenclature \\ Yes, No \\ List of transactions related to the item \\ 4-digit number (Group/Class) \\ Integer number or string \\ Integer number or string \\ Integer number or string
}

\section{Item categories in accordance with IPSAS 12,2-9 and 11, and IPSAS 17}

a. The system shall be capable of grouping items of inventory in accordance with IPSAS 12 (IPSAS 12,2-9 and 11) on the one hand and items of property, plant and equipment in accordance with IPSAS 17 on the other hand. [27]

b. The system shall query the user at the time an item is created in the system to select the appropriate item category in accordance with IPSAS 12 and IPSAS 17 and shall record the selected item category by setting the ItemType to Inventory in the case of an item of inventory and to $P P E$ in the case of an item of property, plant and equipment. [27]

c. In the case the ItemType is set to PPE the system shall process the item in accordance with IPSAS 17 Property, Plant and Equipment, which is described in a separate requirements document. [27]

\section{Exchange Transactions and Non-Exchange Transactions in accordance with IPSAS}

\section{9 and 17 and IPSAS 9}

a. The system shall be capable of grouping items of inventory that have been obtained by the entity as the result of an exchange transaction on the one hand and items of inventory that have been obtained by the entity as the result of a non-exchange transaction on the other hand. [28]

b. The system shall query the user at the time an item is created in the system to select the appropriate item property and shall record the selected item category by setting ItemTransactionType to ExchangeTransaction in the case of an item of inventory obtained by the entity as the result of an exchange transaction and to NonExchangeTransaction in the case of an item of inventory obtained by the entity as the result of a non-exchange transaction. [28] 
4. Ordinarily interchangeable items and non-ordinarily interchangeable items in accordance with IPSAS 12.9

a. The system shall be capable of grouping items of inventory that are ordinarily interchangeable on the one hand and items of inventory that are non-ordinarily interchangeable on the other hand. [29]

b. The system shall query the user at the time an item is created in the system to select the appropriate item property and shall record the selected item property by setting ItemInterchangeable to OrdinarilyInterchangeable in the case of an item of inventory that is ordinarily interchangeable and to NotOrdinarilyInterchangeable in the case of an item of inventory that is not ordinarily interchangeable. [29]

5. Measurement of inventory items resulting from exchange transactions in accordance with IPSAS 12.18-27

a. The system shall query the user to enter the monetary amount for the item of inventory's cost of purchase and any other applicable costs. [30]

b. The system shall set the value of the item of inventory's ItemCost property to the sum of the monetary amount for the cost of purchase and of all other costs entered by the user. [30]

c. The system shall set the initial value of ItemCarryingAmount to the value of the ItemCost calculated in the preceding step. [30]

6. Measurement of inventory items purchased on deferred settlement terms in accordance with IPSAS 12.27

a. The system shall be capable of grouping items of inventory that have been purchased on deferred settlement terms on the one hand and items of inventory that have not been purchased on deferred settlement terms on the other hand. [31]

b. The system shall query the user at the time the purchased item of inventory is recorded in the system to select the appropriate item property and shall record the selected item property by setting ItemDeferredSettlement to Yes in the case of an item of inventory that has been purchased on deferred settlement terms and to No in the case of an item of inventory that has not been purchased on deferred settlement terms. [31]

c. If ItemDeferredSettlement has the value Yes, the system shall query the user to enter the financing element of the purchase of the inventory item and shall record the amount of the financing element in ItemFinancingElement. Then the system shall query the user for the apportioning of the financing element over the period of the financing and shall record the apportioning in ItemFinancingElementApportioning. [31]

7. Measurement of inventory items resulting from non-exchange transactions in accordance with IPSAS 12.18-27

a. The system shall query the user to enter the monetary amount for the item of inventory's fair value cost and shall record this amount in ItemFairValue. [30]

b. The system shall set the value of ItemCarryingAmount to the value of the ItemFairValue entered in the preceding step. [30]

8. Items of inventory held for distribution at no charge or for a nominal charge in accordance with IPSAS 12.18-27

a. The system shall be capable of grouping items of inventory held for distribution at no charge or for a nominal charge on the one hand and items of inventory not held for distribution at no charge or for a nominal charge on the other hand. [30]

b. The system shall query the user at the time an item is created in the system to select the appropriate item category and shall record the selected item category by setting ItemDistribution to Yes in the case of an item of inventory held for distribution at no charge or for a nominal charge and to No in the case of an item of inventory not held for distribution at no charge or for a nominal charge. [30]

c. The system shall allow the user to change the value of ItemDistribution at a later point in time after the item has been created in the system. [30] 
9. Measurement of inventory items held for distribution at no charge or for a nominal charge in accordance with IPSAS 12.18-27

a. In the case that ItemDistribution has the value Yes, the system shall query the user to enter the monetary amount for the item of inventory's current replacement cost and shall set ItemCurrentReplacementCost to the monetary amount entered in the preceding step from the amounts entered by the user. [30]

b. Then the system shall set ItemCarryingAmount to the lower of ItemCost and ItemCurrentReplacementCost of the item of inventory. [30]

10. Measurement of non-ordinarily interchangeable inventories resulting from exchange transactions in accordance with IPSAS 12.32-37

a. If ItemInterchangeable has the value OrdinarilyInterchangeable the system shall apply the procedure listed below under 11. [32]

b. If ItemInterchangeable has the value NotOrdinarilyInterchangeable the system shall query the user to enter the monetary amount for the cost of purchase and any other applicable costs. [32]

c. The system shall set the value of the item of inventory's ItemCost property to the sum of monetary amount for the cost of purchase and of all other costs entered by the user. [32]

d. The system shall set the initial value of ItemCarryingAmount to the value of the ItemCost calculated in the preceding step. [32]

11. Cost formulas for ordinarily interchangeable items of inventory in accordance with IPSAS 12.35-37

a. The system shall be capable of grouping items of inventory for which the first-in-first-out cost formula is used on the one hand and items of inventory for which the weighted average cost formula is used on the other hand. [32]

b. The system shall query the user at the time an item is created in the system to select the cost formula for an item of inventory and shall record the selected item property by setting ItemCostFormula to FirstInFirstOut in the case of an item of inventory for which the first-infirst-out cost formula is used and to WeightedAverageCost in the case of an item of inventory for which the weighted average cost formula is used. [32]

c. The system shall allow the user to change the value of ItemCostFormula at a later point in time after the item has been created in the system. [32]

12. Measurement of ordinarily interchangeable inventories resulting from exchange transactions in accordance with IPSAS 12.32-37

a. If ItemInterchangeable has the value NotOrdinarilyInterchangeable the system shall apply the procedure listed above under 10. [32]

b. If ItemInterchangeable has the value OrdinarilyInterchangeable the system shall query the user to enter the monetary amount for the cost of purchase and any other applicable costs. [32]

c. If ItemCostFormula has the value of FirstInFirstOut the system shall recalculate ItemCarryingAmount in accordance with the first-in-first-out cost formula with the monetary amounts entered by the user in above step b. [32]

d. If ItemCostFormula has the value of WeightedAverageCost the system shall recalculate ItemWeightedAverageCost in accordance with the weighted average cost formula and shall then recalculate ItemCarryingAmount in accordance with the weighted average cost formula with the monetary amounts entered by the user in above step b. [33]

13. Wrtiting down inventory items to net realisable value in accordance with IPSAS 12.38-42

a. The system shall query the user if an item of inventory has become wholly or partially obsolete and let the user select this item from the items of inventory stored in the system. [33]

b. Then the system shall query the user for the monetary value equivalent to the full or partial obsolescence of the inventory item in accordance and shall set ItemWriteDownAmount to this monetary amount. [33]

c. Then thesystemshall reducetheitem of inventory's ItemCarryingAmount by ItemWriteDownAmout. [33] 
14. Reversing the previous write down of inventory items to net realisable value in accordance with IPSAS 12.38-42

a. The system shall query the user for which inventory item the reason for the prior period writedown no longer exists and let the user select this item from items of inventory stored in the system. [33]

b. Then the system shall query the user for the monetary amount equivalent to the degree to which the full or partial obsolescence no longer exists and shall set the item of inventory's ItemReversedWriteDownAmount to this monetary amount. [33]

c. Then the system shall add the value of ItemReversedWriteDownAmount to the item of inventory's ItemCarryingAmount. [33]

\section{Recording the asset account of an item of inventory}

a. The system shall be capable of recording the asset account to be used for an item of inventory. [26]

b. The system shall query the user at the time an item is created in the system to enter the asset account to be used for the item and shall record the selected asset account by setting ItemAssetAccount to the selected asset account. [26]

c. The system shall allow the user to change the value of ItemAssetAccount at a later point in time after the item has been created in the system. [26]

\section{Recording the expense account of an item of inventory}
a. The system shall be capable of recording the expense account to be used for an item of inventory. [26]
b. The system shall query the user at the time an item is created in the system to enter the expense account to be used for the item and shall record the selected expense account by setting ItemExpenseAccount to the selected expense account. [26]
c. The system shall allow the user to change the value of ItemExpenseAccount at a later point in time after the item has been created in the system. [26]

17. Recognising the sale, exchange or distribution of non-ordinarily interchangeable inventory items as an expense, when there is related revenue in accordance with IPSAS 12.44-46
a. The system shall query the user which inventory item is being sold, exchanged, or distributed. [34]
b. If the value of ItemInterchangeable is NonOrdinarilyInterchangeable the system shall record the value of ItemCarryingAmount in the expense account specified in ItemExpenseAccount and in the asset account specified in ItemAssetAccount together with the date when the related revenue is realised. [34]
c. Then the system shall set the value of the ItemCarryingAmount property of the inventory item to zero. [34]

18. Recognising the sale, exchange or distribution of an ordinarily interchangeable inventory item as an expense, when there is related revenue in accordance with IPSAS 12.44-46

a. The system shall query the user which inventory item is being sold, exchanged, or distributed. [34]

b. If the value of ItemInterchangeable is OrdinarilyInterchangeable the system shall query the user for the quantity of items to be sold, exchanged or distributed. [34]

c. If the quantity of items to be sold, exchanged or distributed is less or equal than ItemQuantity, the system shall calculate the expense amount in accordance with the first-in-first-out formula in the case ItemCostFormula has the value FirstInFirstOut or with the weighted-average-costformula in the case ItemCostFormula has the value WeightedAverageCost. [34]

d. Then the system shall record the expense amount calculated in the preceding step c in the expense account specified in ItemExpenseAccount and in the asset account specified in ItemAssetAccount together with the date when the related revenue is realised. [34]

e. Then the system shall reduce ItemQuantity by the quantity entered and reduce the value of the ItemCarryingAmount property by the expense amount calculated in the preceding step c. [83] 
19. Recognising the sale, exchange or distribution of non-ordinarily interchangeable inventory item as an expense, when there is no related revenue in accordance with IPSAS 12.44-46

a. If the value of ItemInterchangeable is NonOrdinarilyInterchangeable the system shall record the value of ItemCarryingAmount in the expense account specified in ItemExpenseAccount and in the asset account specified in ItemAssetAccount together with the date when the related revenue is realised. [34]

b. Then the system shall set the value of the ItemCarryingAmount property of the inventory item to zero. [34]

20. Recognising the sale, exchange or distribution of an ordinarily interchangeable inventory item as an expense, when there is no related revenue in accordance with IPSAS 12.44-46

a. The system shall query the user which inventory item is being sold, exchanged, or distributed. [34]

b. If the value of ItemInterchangeable is OrdinarilyInterchangeable the system shall query the user for the quantity of items to be sold, exchanged or distributed. [34]

c. If the quantity of item to be sold, exchanged or distributed is less or equal than ItemQuantity, the system shall calculate the expense amount in accordance with the first-in-first-out formula in the case ItemCostFormula has the value FirstInFirstOut or with the weighted-average-costformula in the case ItemCostFormula has the value WeightedAverageCost. [34]

d. Then the system shall record the expense amount calculated in the preceding step $\mathrm{c}$ in the expense account specified in ItemExpenseAccount and in the asset account specified in ItemAssetAccount together with the date when the related revenue is realised. [34]

e. Then the system shall reduce ItemQuantity by the quantity entered and reduce the value of the ItemCarryingAmount property by the expense amount calculated in the preceding step c. [34]

21. Calculation of the total carrying amount of all inventory items in accordance with IPSAS 12.47-50

a. The system shall calculate the total carrying amount of all items of inventory as the sum of the ItemCarryingAmount properties of the individual inventory items. [35]

b. The system shall output the total carrying amount of all item of inventory. [35]

22. Calculation of the carrying amount of inventory items in classifications in accordance with IPSAS 12.47-50

a. The system shall be capable of reporting the carrying amounts of inventory items by the common classifications of inventories, merchandise, production supplies, materials, work in progress, finished goods or by user-defined classifications. [35]

b. The system shall calculate and output for each classification of inventories the sum of the respective inventory items. [35]

23. Calculation and output of the carrying amount of inventory items carried at fair value less costs to sell in accordance with IPSAS 12.47-50
a. The system shall query the user which inventory items are carried at fair value less costs to sell (i.e. at residual value). [35]
b. The system shall calculate and output the sum of those inventory items carried at fair value less costs to sell. [35]

24. Calculation and output of the amount of inventories recognised as an expense during the accounting period in accordance with IPSAS 12.47-50
a. The system shall calculate and output for each expense account the amount of inventories recognised as an expense during the accounting period. [35]

25. Calculation and output of the amount of write-downs of inventories recognised as an expense during the accounting period in accordance with IPSAS 12.47-50

a. The system shall calculate and output for each classification of inventories the sum of the respective inventory items. [35] 
26. Calculation and output of the amount of reversals of write-downs of inventories recognised as an expense during this accounting period or prior accounting periods in accordance with IPSAS 12.47-50

a. The system shall calculate and output for each classification of inventories the sum of the ItemReversedWriteDownAmounts. [35]

27. Calculation of the carrying amount of inventories pledged as security in accordance with IPSAS 12.47-50

a. The system shall query the user which items of inventory have been pledged as security. [35]

b. The system shall calculate and output the sum of the ItemCarryingAmounts of all items of inventory items that have been pledged as security. [35]

\section{Conclusion and outlook}

The above discussion has shown that — in principle - exemplary requirements for the compliance of military logistics systems can be derived from IPSAS 12-Inventories.

However, several of the found requirements such as e.g. requirement 16 Recording the expense account of an item of inventory directly confirm the opinion of Chan that IPSAS implicitly take for granted that an "accounting system with sophisticated features" has already been implemented and that such an accounting system is based both on double-entry book-keeping and on the IPSAS accounting equation and has inter alia a sufficiently detailed chart of accounts [2]. The wide-ranging requirements that hide behind these "sophisticated features" can be seen e.g. in the Generally Accepted Principles for IT-based Accounting Systems (Grundsätze ordnungsmäßiger DV-gestützter Buchführungssysteme) issued by the German Federal Ministry of Finance [36].

Following Grady the process of requirements integration ensures that all requirements of a system taken together, i.e. "the complete set of requirements" [22: 395] are reduced to the minimum number of requirements, complete and balanced, and are mutually consistent. [22: 395] IPSAS 12 requirements therefore would need to be integrated with regard to requirements derived from other IPSASs and with requirements related to the link of the military logistics system with the accounting system used to prepare IPSAS annual financial statements.

More likely than not the exemplary IPSAS 12 requirements proposed above need to be noticeably changed and/or augmented depending on the characteristics of the accounting system used and other factors external to the military logistics system.

From the text of IPSAS 12 it is not a straightforward move to derive concrete requirements for the historical data that have to be stored for an item, such as transaction history, which is of high relevance, e.g. for writing down the carrying amount of an item and possibly reversing fully or partially this write down in later accounting periods. Additionally, the practical effort for storing large amounts of historical data for items with a high turnover but small individual carrying amount can be expected to be considerable

Another issue in which further research would be desirable would be to explore, if other ways of documenting requirements, such as using models, graphics or tables are better suitable for documenting IPSAS requirements than the written (narrative) requirements proposed in this paper. [22: 395] 


\section{References}

[1] SCHEPPELMANN, H.: Reusing military logistics data for IPSAS financial reporting: Benefits and possible limitations. Academic and Applied Research in Military Science. 112 (2012), 225-232.

[2] CHAN, J. L.: International Public Sector Accounting Standards: Conceptual and Institutional Issues. In. M. D’Amore (Ed.), The Harmonization of Government Accounting and the Role of IPSAS. New York: McGraw-Hill, 2009. 19-33.

[3] International Public Sector Accounting Standards Board (IPSASB): Handbook of International Public Sector Accounting Pronouncements. 2013 Edition, The Conceptual Framework for General Purpose Financial Reporting by Public Sector Entities, Chapter 3: Qualitative Characteristics, 50-68. http://www.ifac.org/sites/default/files/publications/files/ Volume\%201_0.pdf (downloaded: 2308 2013)

[4] International Public Sector Accounting Standards Board (IPSASB): Handbook of International Public Sector Accounting Pronouncements. 2013 Edition, IPSAS 12 369-386. IPSAS 532-571.

[5] ISACA: IS Auditing Guideline, Enterprise Resource Planning Systems Review. Document G21, 01052003.

[6] ISACA: Vorgehensmodell Anwendungsprüfung. Switzerland Chapter, 2010.

[7] United States General Accounting Office: Inventory System Checklist - Systems Reviewed Under the Federal Financial Management Improvement Act of 1996. GAO/AIMD-9821.2.4. 1998. http://www.gao.gov/assets/80/76355.pdf (downloaded: 2308 2013)

[8] International Public Sector Accounting Standards Board (IPSASB): Handbook of International Public Sector Accounting Pronouncements. 2013 Edition, Preface to International Public Sector Accounting Standards, 19-23.

[9] MÜLLER, T., BERGER, M.: Internationale Rechnungslegung für den öffentlichen Sektor (IPSAS). Grundlagen und Einzeldarstellungen. Stuttgart: Schäffer-Poeschel Verlag, 2008. 5.

[10] International Public Sector Accounting Standards Board (IPSASB): IPSASB Work Plan 2013-15. 2013. https://www.ifac.org/sites/default/files/uploads/IPSASB/IPSASB-WorkPlan-2013-2015.pdf (downloaded: 2308 2013)

[11] European Commission: Commission Regulation (EC) No 1136/2009 of 25 November 2009 amending Regulation (EC) No 1126/2008 adopting certain international accounting standards in accordance with Regulation (EC) No 1606/2002 of the European Parliament and of the Council as regards International Financial Reporting Standard (IFRS) 1. 25 November 2009. http://eur-lex.europa.eu/LexUriServ/LexUriServ. do?uri=OJ:L:2009:311:0006:0020:EN:PDF. (downloaded: 2308 2013)

[12] International Public Sector Accounting Standards Board (IPSASB): Recommended Practice Guideline 1, Reporting on the Long-Term Sustainability of an Entity's Finances. http://www. ifac.org/sites/default/files/publications/files/RPG\%201\%20Long-term\%20Sustainability\%20 of\%20Public\%20Finances\%20DRAFT\%20July\%2016,\%202013_0.pdf (downloaded: 2308 2013)

[13] International Public Sector Accounting Standards Board (IPSASB): Recommended Practice Guideline 2, Financial Statement Discussion and Analysis. http://www.ifac.org/sites/default/ files/publications/files/RPG\%202\%20Financial\%20Statement\%20Discussion\%20and\%20 Analysis\%20July\%2016,\%202013\%20DRAFT.pdf (downloaded: 2308 2013)

[14] Standing Interpretations Committee (SIC): Official interpretations (SICs) of the International Accounting Standards (IAS). http://www.ifrs.org/IFRSs/Pages/SICs.aspx (downloaded: 23 August 2013)

[15] Interpretations Committee (IFRIC): International Financial Reporting Standards Interpretations (IFRICs) of International Financial Reporting Standards. http://www.ifrs.org/ IFRSs/Pages/IFRICs.aspx (downloaded: 2308 2013) 
[16] International Public Sector Accounting Standards Board (IPSASB): Transition to the Accrual Basis of Accounting: Guidance for Public Sector Entities. Third Edition. January 2011. http://www.ifac.org/sites/default/files/publications/files/IPSASB-study-14-3e.pdf. (downloaded: 2308 2013)

[17] BERGMANN, A.: Public Sector Financial Management. Harlow: Financial Times Prentice Hall, 2009. 72-75.

[18] BASTOS, R.: Evaluating the Potential Technology Impact of IFRS. ISACA Journal, 4 (2009), 1-3.

[19] BROWN, W. C.: Questions That Must Be Addressed for a Successful IFRS Implementation. ISACA Journal, 3 (2011), 1-6.

[20] CHRISTIAENS, J., REYNIERS, B.: Impact of IPSAS on Reforming Governmental Financial Information Systems: A Comparative Study. Working Paper. Gent: Ghent University, Faculty of Economics and Business Administration, July 2009.

[21] Deutsche Oracle Anwendergruppe e.V. (DOAG): Version 12 der Oracle E-Business Suite erfüllt die deutschen Grundsätze ordnungsgemäßer Buchführung (GoB). 25 September 2009. http://www.doag.org/de/home/aktuelle-news/article/version-12-der-oracle-e-businesssuite-erfuellt-die-deutschen-grundsaetze-ordnungsgemaesser-buchfueh.html (downloaded: 2308 2013)

[22] GRADY, J. O.: System Requirements Analysis. Burlington: Elsevier, 2006. DOI: https:// doi.org/10.1016/B978-012088514-5/50004-7

[23] BOEHM, B.: A View of 20th and 21st Century Software Engineering. Proceedings of the 28th International Conference on Software Engineering, International Conference on Software Engineering, 2006, 12-29.

[24] BOEHM, B.: Guidelines for Verifying and Validating Software Requirements and Design Specifications. Euro IFIP 79, (1979), 711-719.

[25] United States Department of Defense (DoD): Standard Practice, Defense and ProgramUnique Specifications format and content. MIL-STD-961E with change 1, 02 April 2008.

[26] International Public Sector Accounting Standards Board (IPSASB): IPSAS 12.

[27] International Public Sector Accounting Standards Board (IPSASB): IPSAS 12.2-9 and 11 and IPSAS 17.

[28] International Public Sector Accounting Standards Board (IPSASB): IPSAS 12.9 and 17 and IPSAS 9.

[29] International Public Sector Accounting Standards Board (IPSASB): IPSAS 12.9.

[30] International Public Sector Accounting Standards Board (IPSASB): IPSAS 12.18-27.

[31] International Public Sector Accounting Standards Board (IPSASB): IPSAS 12.27.

[32] International Public Sector Accounting Standards Board (IPSASB): IPSAS 12.32-37.

[33] International Public Sector Accounting Standards Board (IPSASB): IPSAS 12.38-42.

[34] International Public Sector Accounting Standards Board (IPSASB): IPSAS 12.44-46.

[35] International Public Sector Accounting Standards Board (IPSASB): IPSAS 12.47-50.

[36] German Federal Ministry of Finance (Bundesfinanzministerium): Schreiben des Bundesministeriums der Finanzen an die obersten Finanzbehörden der Länder vom 7. November 1995 - IV A 8 - S 0316 - 52/95- BStBl 1995 I S. 738. Grundsätze ordnungsmäßiger DV-gestützter Buchführungssysteme. 